Article

\title{
Evaluating the Marginal Land Resources Suitable for Developing Pistacia chinensis-Based Biodiesel in China
}

\author{
Lu Lu ${ }^{1,2}$, Dong Jiang ${ }^{1, *}$, Dafang Zhuang ${ }^{1}$ and Yaohuan Huang ${ }^{1}$
}

1 State Key Laboratory of Resources and Environmental Information Systems, Institute of Geographical Sciences and Natural Resources Research, Chinese Academy of Sciences, Beijing 100101, China; E-Mails: zhuangdf@igsnrr.ac.cn (D.Z.); huangyh@lreis.ac.cn (Y.H.)

2 College of Resources and Environmental Sciences, Nanjing Agricultural University, Nanjing 210095, China; E-Mail: 2010103054@njau.edu.cn

* Author to whom correspondence should be addressed; E-Mail: jiangd@igsnrr.ac.cn; Tel.: +86-10-6488-9433; Fax: +86-10-6485-5049.

Received: 29 April 2012; in revised form: 14 June 2012 / Accepted: 26 June 2012 / Published: 29 June 2012

\begin{abstract}
Bio-energy from energy plants is expected to play an increasing role in the future energy system, with benefits in terms of reducing greenhouse gas emissions and improving energy security. Pistacia chinensis is believed to be one of the most promising non-food input for biodiesel production. This study focused on the marginal land availability for developing Pistacia chinensis-based bioenergy in China. The spatial distribution, quality and total amount of marginal land resources suitable for cultivating Pistacia chinensis were identified with multiple datasets (natural habitat, remote sensing-derived land use, meteorological and soil data) and geoinformatic techniques. The results indicate that the area of marginal land exploitable for Pistacia chinensis plantations in China is 19.90 million hectares, which may produce approximately 56.85 million tons of biodiesel each year. The spatial variation of both marginal land resources and biodiesel potential are also presented. The results can be useful for national and regional bio-energy planning.
\end{abstract}

Keywords: Pistacia chinensis; marginal land; biodiesel 


\section{Introduction}

In recent years, energy demand is rapidly increasing both in developed and developing countries. Bioenergy from energy plants is expected to play an increasing role in the future energy system, with benefits in terms of greenhouse gas emissions and energy security [1,2]. Energy plants, also known as biomass fuel plants, refer to those plants that are rich in fat and can be burned or decomposed to produce energy similar to oil or as the substitute for oil [3]. Crops such as wheat, corn and soybeans can be used as bioenergy sources, while non-food plants such as Jatropha curcas L. and Pistacia chinensis are attracting more attention for developing a sustainable bioenergy industry. Throughout the World, there are extensive areas of marginal land that are unsuitable for crop production, but ideal for the growth of energy plants with high stress resistance. These lands include barren mountains, barren lands and alkaline lands. Rational exploitation of marginal land resources suitable for energy production, high-yield energy plants and liquid fuel derived from biomass are some of the most effective measures to coping with fossil energy depletion and developing alternative energy sources [4]. In China, for example, energy plant species including cassava, Jatropha curcas L., Pistacia chinensis and Jerusalem artichoke are specified in the new energy development strategy in the Twelfth Five-year Plan.

Evidence indicates that previous evaluations have generally overestimated bioenergy potential, suggesting that bioenergy policy targets based on those previous evaluations could be unrealistic [5]. Therefore, accurate assessments of the potential of energy plants have become an important topic of research. Relevant research [5-9] has been conducted on the evaluation of potential of biodiesel from non-food energy plants. However, little has been done to assess the biodiesel potentials of Pistacia chinensis. Pistacia chinensis, belonging to the family Anacardiaceae, is a deciduous, woody, oil-bearing tree species widely distributed in China [10]. There are some records concerning the distribution of Pistacia chinensis resources. Variety breeding and the growth and exploitation of Pistacia chinensis have been surveyed by both Chinese and foreign scholars [11-16].

The main objective of this paper is to present estimation of spatial distribution, quality and the total amount of marginal land resources suitable for cultivating Pistacia chinensis, using multiple datasets (natural habits data, remote sensing derived land use data, meteorological data and soil data) and geographic information techniques. Biomass and bioenergy potential could then be evaluated based on those data sets. The results provide an operational approach for assessing marginal land resources not only for Pistacia chinensis, but also many other energy plant species. Results of this study were also presented for scientific researches and development of Pistacia chinensis based biodiesels.

\section{Experimental Methods}

\subsection{Data Acquisition}

The study needed land-use, meteorological, terrain (including elevation and slope) and soil data. The land-use data of China at the scale of 1:100,000 were supplied by the Data Center for Resources and Environmental Sciences (RESDC). The meteorological data, presented by the China Meteorological Administration (CMA), include air temperature and precipitation for multiple years for all of China. An authorized terrain dataset at a scale of 1:250,000 was provided by the State Bureau of Surveying and Cartography (SBSC) of China. The soil data were also supplied by RESDC. Soil effective depth, organic 
matter content and soil texture information were derived from more than 1620 in situ soil samples. All data were transformed into raster data layers with the same pixel size $(1000 \mathrm{~m} \times 1000 \mathrm{~m})$ and coordinate system. All datasets are listed in Table 1.

Table 1. General description of the research data.

\begin{tabular}{cccccc}
\hline Factors & Scale & Format & Time & Data sources & Description \\
\hline Land use & $1: 100,000$ & Shape file & 2000 & $\begin{array}{c}\text { Data Center for } \\
\text { Resources and } \\
\text { Environmental } \\
\text { Sciences (RESDC) }\end{array}$ & $\begin{array}{c}\text { Including six first classes } \\
\text { and 25 secondary classes } \\
\text { [17] }\end{array}$ \\
\hline Elevation & $1: 250,000$ & Grid & - & $\begin{array}{c}\text { State Bureau of } \\
\text { Surveying and } \\
\text { Cartography (SBSC) }\end{array}$ & $\begin{array}{c}\text { Used for extracting slope } \\
\text { data }\end{array}$ \\
\hline Climate & $1 \mathrm{~km}$ & Grid & $1971-2000$ & $\begin{array}{c}\text { China Meteorological } \\
\text { Administration (CMA) }\end{array}$ & $\begin{array}{c}\text { Including temperature and } \\
\text { precipitation }\end{array}$ \\
\hline Soil & $1 \mathrm{~km}$ & Grid & - & RESDC & $\begin{array}{c}\text { Including soil effective } \\
\text { depth, organic matter } \\
\text { content and soil texture }\end{array}$ \\
\hline Nature reserve & $1: 100,000$ & Shape file & 2000 & RESDC & Scope of nature reserve area \\
\hline
\end{tabular}

\subsection{Identification and Assessment of Marginal Land Suitable for the Growth of Pistacia chinensis}

Currently, there are many methods for land suitability assessment, including the analytic hierarchy process, agricultural ecology zoning and multi-factor integrated assessment. Multi-factor integrated assessment allows the selection of assessment indicators according to the considered crop features, and it has the advantages of flexibility and suitability $[18,19]$. This method has already been applied to the assessment of use patterns of different lands for different crops [20]. Using multi-factor integrated assessment and modifying the assessment results by social and economic constraints, this paper assesses land suitability for growing Pistacia chinensis. The specific procedures are as follows (Figure 1):

Figure 1. Workflow of spatial distribution and suitability evaluation for energy land resources.

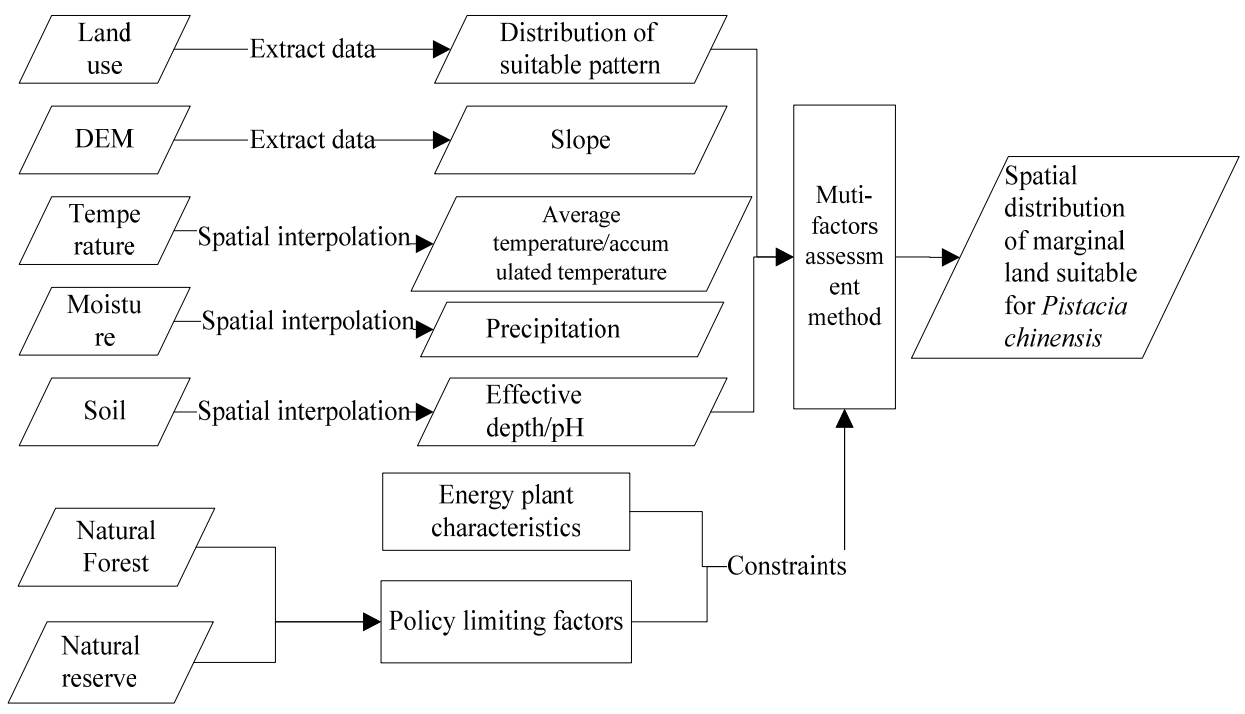


(1) Based on the existing research $[2,12,13,18]$, we extracted the land use types of marginal land suitable for growing Pistacia chinensis: shrub land, sparse forest land, natural grassland (excluding natural protected forest, nature reserve, wild plant and animal reserve, water-source forest reserve, soil and water conservation regions, sparse forest land, shrub land and grassland in shelter forest areas) [21] and unused land (including alkaline land, bare land and shoal/bottomland); (2) Based on the existing references [3,10-13], we set the requirements of Pistacia chinensis for temperature, moisture, soil and slope and divide these natural conditions into three grades: suitable, fairly suitable and unsuitable; (3) Using data of temperature, moisture, soil and slope, we perform a multi-facture suitability assessment of land resources to obtain the distribution areas of suitable, fairly suitable and unsuitable conditions for Pistacia chinensis; (4) Based on social, economic and environmental constraints, we modify the preliminary assessment results.

\subsection{Ecological Suitability Analysis for Pistacia chinensis}

Although no consensus has been reached concerning criteria for grading the suitability of land for Pistacia chinensis Bunge, scholars have conducted studies on suitable temperature, moisture and soil type for growing Pistacia chinensis [10-15,22]. This study constructed a zoning indicator system for natural conditions of growing Pistacia chinensis according to the existing researches.

\subsubsection{Temperature}

Pistacia chinensis is suitable for extensive planting and widely distributed in 23 provinces and districts in North China, Central China and South China, especially in Hebei, Henan, Anhui and Shaanxi [11]. The distribution of Pistacia chinensis stretches across temperate, sub-tropical and tropical zones. These zones have annual mean temperatures of $11.5-21.0{ }^{\circ} \mathrm{C}$, a January mean temperature of $-4.2-17.2{ }^{\circ} \mathrm{C}$, a July mean temperature of $20.8-28.8^{\circ} \mathrm{C}$ and absolute minimum and maximum temperatures of $-23.6{ }^{\circ} \mathrm{C}$ and $43.6{ }^{\circ} \mathrm{C}$, respectively. The annual mean hours of sunshine range from $1550.0 \mathrm{~h}$ to $2696.9 \mathrm{~h}$, and the annual mean frost-free period exceeds 160 days in these areas [10]. Combining research findings with expert opinions, we select the annual mean temperature, annual extreme minimum temperature and $\geq 10{ }^{\circ} \mathrm{C}$ accumulated temperature as the assessment indicators (Table 2).

\subsubsection{Precipitation}

The precipitation of the distribution areas of Pistacia chinensis in China varies significantly from $400 \mathrm{~mm}$ to $4000 \mathrm{~mm}$. The annual mean precipitation of the major areas of Pistacia chinensis is 400.0-2371.3 $\mathrm{mm}$ [3]. Studies show that areas with an annual precipitation over $300 \mathrm{~mm}$ are suitable for the growth of Pistacia chinensis. According to the survey statistics [10], the primary concentration areas of Pistacia chinensis have an annual precipitation of $400-750 \mathrm{~mm}$, and that in secondary concentration areas is $694.5-1864.7 \mathrm{~mm}$. Based on these statistics, the suitability grading for water conditions in the growth areas of Pistacia chinensis is comprehensively considered (Table 2). 


\subsubsection{Soil}

Pistacia chinensis, with its deep roots and high resistance to drought and barrenness, can adapt to a wide range of soil $\mathrm{pH}$ values; it can also grow on the dry, sunny slopes of limestone mountains. The parent rock of the soil is mainly limestone, with cinnamon soil as the dominant soil type. The soil has a $\mathrm{pH}$ value of 5.5-7.8, and the soil depth can vary from 0 (bare rocks) to $50 \mathrm{~cm}$. However, there is no universally accepted criterion for the selection of a soil assessment indicator. According to existed literatures, soil with organic matter content above $1.5 \%$ as suitable for the growth of Pistacia chinensis, and the effective soil depth is selected as the soil assessment indicator (Table 2).

\subsubsection{Slope}

According to China's environmental protection policy, we set the upper limit of soil slopes suitable for the growth of Pistacia chinensis at $25^{\circ}$; slopes above $25^{\circ}$ are vulnerable to severe water loss and soil erosion and are therefore unsuitable for cultivation [18]. The suitability grade for slopes is divided according to the plantation requirements of Pistacia chinensis as an energy plant species (Table 2).

Table 2. Temperature, moisture and soil under three categories of land suitability for Pistacia chinensis plantations.

\begin{tabular}{ccccc}
\hline Item & State & Suitable & Fairly suitable & Unsuitable \\
\hline \multirow{2}{*}{ Temperature } & $\begin{array}{c}\text { Annual average } \\
\text { temperature } /{ }^{\circ} \mathrm{C}\end{array}$ & $11.5-15.9$ & $\begin{array}{c}5.8-11.5 \text { or } \\
15.9-28.4\end{array}$ & $\leq 5.8$ or $\geq 28.4$ \\
\cline { 2 - 5 } & $\begin{array}{c}\text { Annual average extreme } \\
\text { minimum temperature } /{ }^{\circ} \mathrm{C}\end{array}$ & $\geq-15$ & $-26.5--15$ & $\leq-23.6$ \\
\cline { 2 - 5 } & $\begin{array}{c}\text { Accumulated temperature } \\
\text { greater than or } 10{ }^{\circ} \mathrm{C} /{ }^{\circ} \mathrm{C} \cdot \mathrm{d}\end{array}$ & $\geq 3800$ & $1180-3800$ & $\leq 1180$ \\
\hline Water condition & Precipitation $/ \mathrm{mm}$ & $400-1300$ & $1300-1900$ & $\geq 1900$ or $\leq 400$ \\
\hline Soil & Effective depth $/ \mathrm{cm}$ & 60 & 30 & $\leq 30$ \\
\hline DEM & Slope $/{ }^{\circ}$ & 15 & 25 & $\geq 25$ \\
\hline
\end{tabular}

\section{Results and Discussion}

Using the above data and research methods, we assessed the suitability of China's land resources for growing Pistacia chinensis as a raw material to derive biological liquid fuel. A multi-factor integrated assessment is adopted, and the assessment results are modified by economic, social and environmental factors.

\subsection{Multi-Factor Integrated Assessment Results of Land Suitability for the Growth of Pistacia chinensis}

\subsubsection{National Assessment Results}

Following the principles of multi-factor integrated assessment, the statistical process is performed on the suitability grade of each single factor and the type of land use to obtain the land suitability:

(1) In compliance with the principle that bioenergy development should not compete with land for grain cultivation, we exclude cultivated land. Finally, we selected six land use types as the suitable 
ones for growing Pistacia chinensis; (2) To avoid competition with ecologically protected land, all the lands in national reserves are excluded; (3) Considering the transportation costs, we define that the minimum continuous growth area should be no less than 200 ha in large-scale exploitation [20]; (4) Applying the evaluation criteria for suitable, fairly suitable and unsuitable for temperature, moisture, soil and slope, we obtain the spatial distribution of land suitability for the growth of Pistacia chinensis (as shown in Figure 2).

Figure 2. Spatial distribution of marginal land suitable for Pistacia chinensis in China.

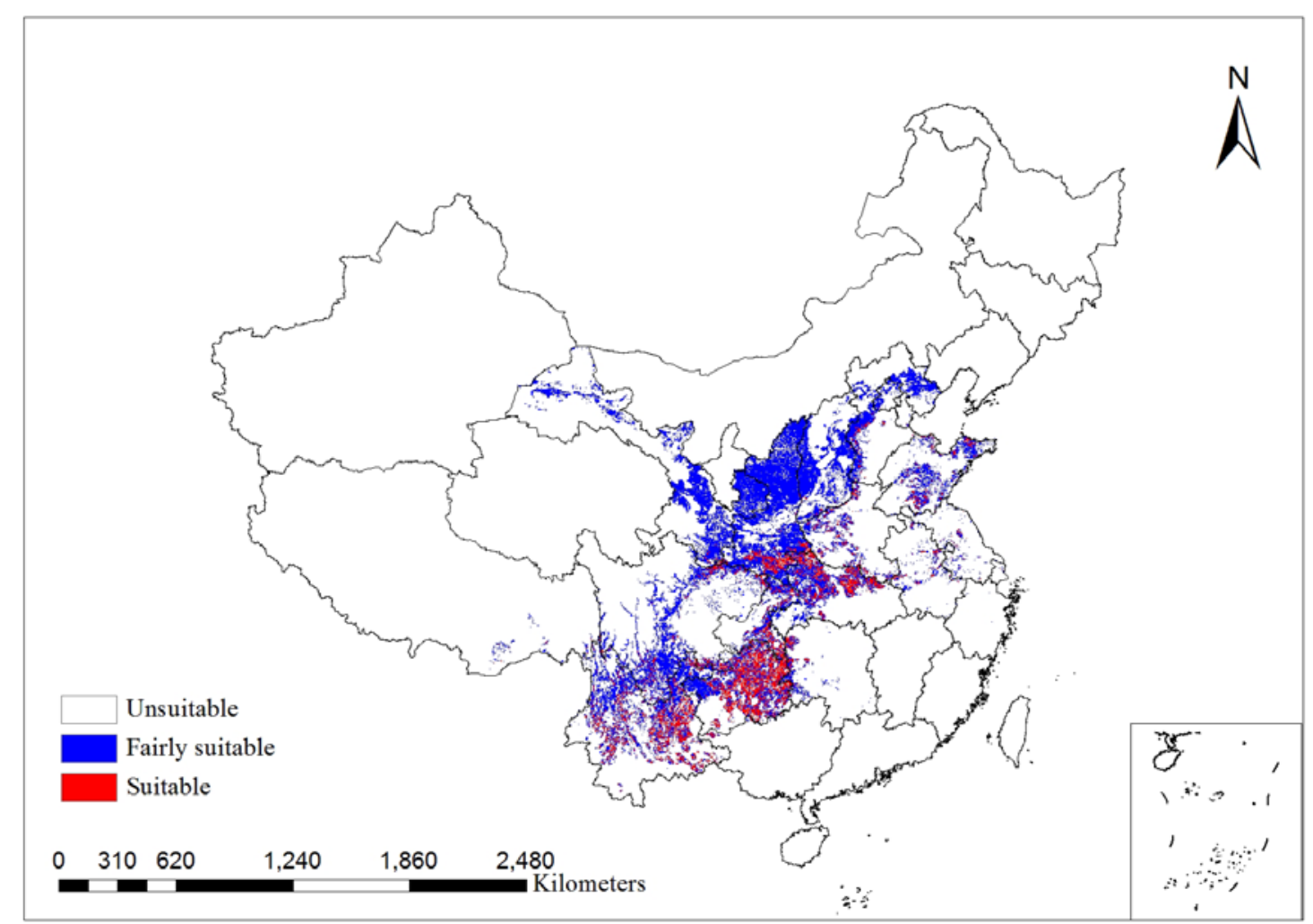

From Figure 2, we can see that the spatial distribution of marginal lands suitable for the growth of Pistacia chinensis in China generally shows a northeast-southwest trend. Areas suitable and fairly suitable for the growth of Pistacia chinensis form two obvious trend lines from northeast to southwest. These areas are mainly concentrated in the Taihangshan Mountains in North China, Central China, the Loess Plateau in Northwest China and the Yunnan-Guizhou plateau in Southwest China. In the coastal areas in Southeast China (e.g., Shandong, Jiangsu, Zhejiang and Guangdong), the economy is more developed and the land use intensity is high. Agricultural use and construction use are two major types of land use; therefore, there is much less land area left for the growth of Pistacia chinensis Bunge. Generally, the marginal land suitable for the growth of Pistacia chinensis is continuously distributed, such as Hebei, Henan, Shanxi, Shaanxi, Ningxia and Gansu in the north and Yunnan, Guizhou, Chongqing and Hubei in the south. In some districts, such as Sichuan and Shandong, the growth areas of Pistacia chinensis are discontinuously distributed, or they have a scattered distribution, as in Anhui, Jiangsu, Hunan and Tibet. Hou et al. [10] conducted a field investigation of China's Pistacia chinensis resources over a period of several years, and they obtained the geographical distribution of Pistacia chinensis. The general distribution trend was from northeast to southwest, with the concentration areas 
in Hebei, Henan, Shanxi and Shaanxi. This finding corresponds well with our assessment result.

Based on the obtained spatial distribution of marginal land suitability and using spatial zonal statistical function of ARCGIS software, we analyze the suitability of China's marginal land use according to different land type for the growth of Pistacia chinensis (as shown in Figure 3).

Figure 3. Land use type areas of suitable and fairly suitable land for planting Pistacia chinensis.

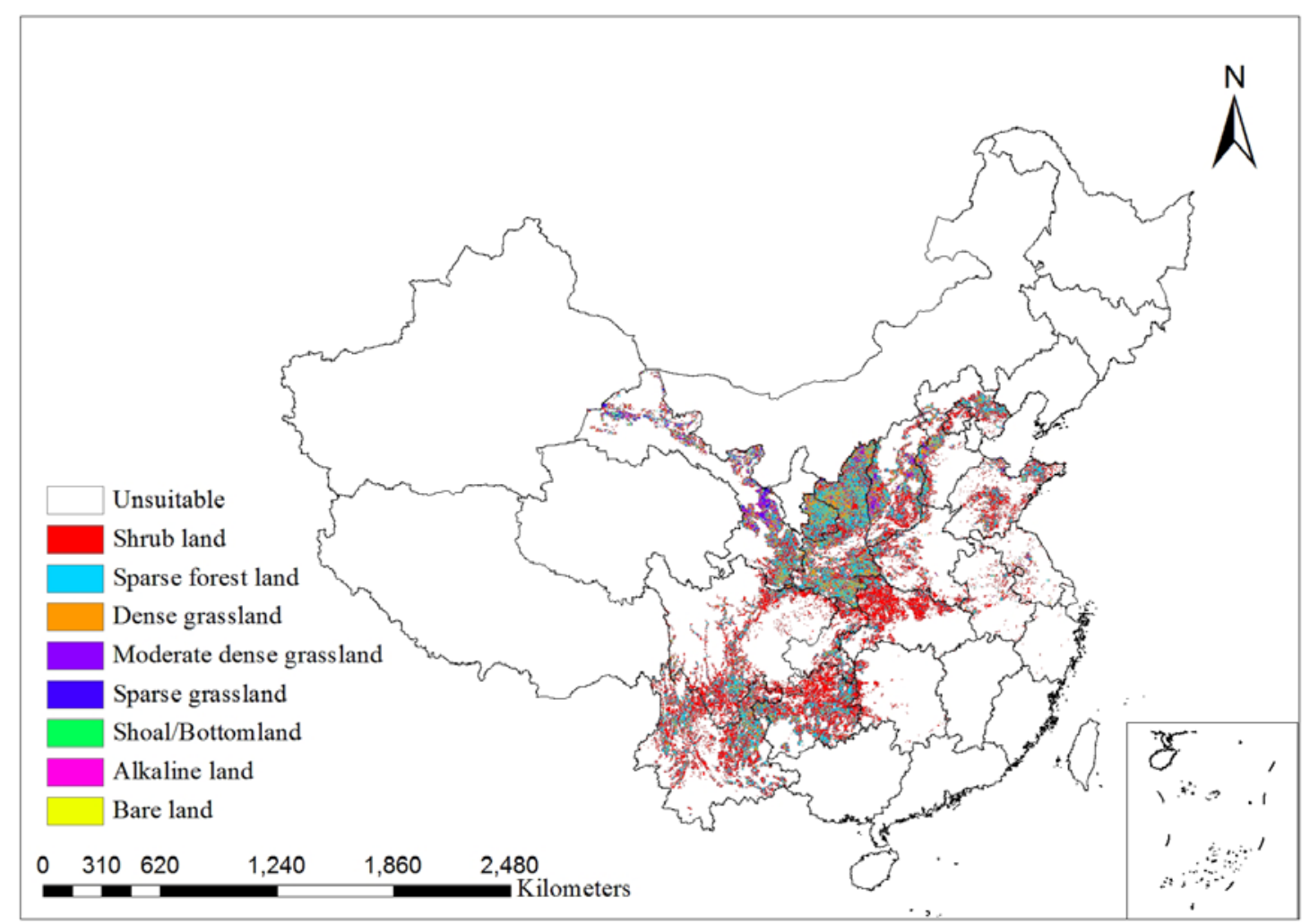

The results show that among the various types of marginal lands, the area suitable for the growth of Pistacia chinensis is 18.28 million ha, and the fairly suitable area is 27.57 million ha. The production potential of Pistacia chinensis is considerable. Shrub land is the dominant land type suitable for the growth of Pistacia chinensis, which accounts for $35.23 \%$ of the total suitable area. Sparse forest land and moderate dense grassland come next, accounting for $23.91 \%$ and $20.82 \%$ of the total suitable area, respectively. The sum of the area of the three land types accounts for $79.96 \%$ of the total suitable area.

\subsubsection{Provincial Assessment Results National Assessment Results}

Although the total land resources suitable or fairly suitable for the growth of Pistacia chinensis are abundant, the provincial differences are significant. Overall, the spatial distribution of marginal land suitable for the growth of Pistacia chinensis is more concentrated in Central and Southwest China than in the coastal areas in Southeast China (as shown in Tables 3 and 4). 
Table 3. Evaluation results of marginal land of each province suitable for planting Pistacia chinensis (million ha).

\begin{tabular}{|c|c|c|c|c|c|c|c|c|c|}
\hline $\begin{array}{c}\text { Provinces } \backslash \\
\text { land use type }\end{array}$ & $\begin{array}{c}\text { Shrub } \\
\text { land }\end{array}$ & $\begin{array}{c}\text { Sparse } \\
\text { forest land }\end{array}$ & $\begin{array}{c}\text { Dense } \\
\text { grassland }\end{array}$ & $\begin{array}{c}\text { Moderate dense } \\
\text { grassland }\end{array}$ & $\begin{array}{c}\text { Sparse } \\
\text { grassland }\end{array}$ & $\begin{array}{c}\text { Shoal/ } \\
\text { bottomland }\end{array}$ & $\begin{array}{c}\text { Alkaline } \\
\text { land }\end{array}$ & $\begin{array}{l}\text { Bare } \\
\text { land }\end{array}$ & Sum \\
\hline Beijing & 0.0008 & 0.0016 & 0.0033 & 0.0014 & 0.0005 & 0.0015 & 0 & 0 & 0.0091 \\
\hline Hebei & 0.0084 & 0.006 & 0.097 & 0.0829 & 0.0492 & 0.0522 & 0.0005 & 0.0005 & 0.2967 \\
\hline Shanxi & 0.0221 & 0.018 & 0.0314 & 0.0223 & 0.0666 & 0.0071 & 0.0007 & 0 & 0.1682 \\
\hline Anhui & 0.0904 & 0.0104 & 0.2166 & 0.0006 & 0.0002 & 0.0327 & 0 & 0 & 0.3509 \\
\hline Shandong & 0.0665 & 0.0576 & 0.1923 & 0.3719 & 0.1599 & 0.0629 & 0.0661 & 0.0004 & 0.9776 \\
\hline Henan & 0.2201 & 0.103 & 0.3695 & 0.2232 & 0.0314 & 0.0714 & 0.0002 & 0.0001 & 1.0189 \\
\hline Hubei & 0.9248 & 1.0966 & 0.0852 & 0.0783 & 0.0026 & 0.0197 & 0 & 0.0002 & 2.2074 \\
\hline Hunan & 0.1191 & 0.2903 & 0.0385 & 0.0135 & 0.0011 & 0.0004 & 0 & 0.0002 & 0.4631 \\
\hline Chongqing & 0.3821 & 0.2945 & 0.0493 & 0.2462 & 0.0074 & 0.0004 & 0 & 0 & 0.9799 \\
\hline Sichuan & 0.5256 & 0.4149 & 0.2365 & 0.2774 & 0.0102 & 0.0122 & 0 & 0 & 1.4768 \\
\hline Guizhou & 2.1594 & 0.9251 & 0.0943 & 0.8686 & 0.0979 & 0.0003 & 0 & 0 & 4.1456 \\
\hline Yunnan & 1.7652 & 0.9441 & 1.0703 & 0.8366 & 0.0215 & 0.0018 & 0 & 0.0019 & 4.6414 \\
\hline Shaanxi & 0.0661 & 0.1466 & 0.1461 & 0.7295 & 0.0533 & 0.0162 & 0.0023 & 0.0001 & 1.1602 \\
\hline Gansu & 0.0047 & 0.0018 & 0.0059 & 0.0447 & 0.005 & 0 & 0 & 0 & 0.0621 \\
\hline Jiangsu & 0.0251 & 0.0447 & 0.027 & 0.0021 & 0.0004 & 0.078 & 0 & 0 & 0.1773 \\
\hline Tibet & 0.0585 & 0.0153 & 0.0625 & 0.0059 & 0.0001 & 0.0001 & 0 & 0 & 0.1424 \\
\hline Sum & 6.4389 & 4.3705 & 2.7257 & 3.8051 & 0.5073 & 0.3569 & 0.0698 & 0.0034 & 18.2776 \\
\hline
\end{tabular}

Table 4. Evaluation results of marginal land of each province fairly suitable for planting Pistacia chinensis (million ha).

\begin{tabular}{cccccccccc}
\hline $\begin{array}{c}\text { Provinces } \backslash \\
\text { land use type }\end{array}$ & $\begin{array}{c}\text { Shrub } \\
\text { land }\end{array}$ & $\begin{array}{c}\text { Sparse } \\
\text { forest land }\end{array}$ & $\begin{array}{c}\text { Dense } \\
\text { grassland }\end{array}$ & $\begin{array}{c}\text { Moderate dense } \\
\text { grassland }\end{array}$ & $\begin{array}{c}\text { Sparse } \\
\text { grassland }\end{array}$ & $\begin{array}{c}\text { Shoal/ } \\
\text { bottomland }\end{array}$ & $\begin{array}{c}\text { Alkaline } \\
\text { land }\end{array}$ & $\begin{array}{c}\text { Bare } \\
\text { land }\end{array}$ & Sum \\
\hline Beijing & 0.1692 & 0.0693 & 0.0853 & 0.011 & 0.0048 & 0.0079 & 0 & 0 & 0.3475 \\
Hebei & 0.7086 & 0.1645 & 0.9201 & 0.3249 & 0.0878 & 0.0576 & 0.0024 & 0.0012 & 2.2671 \\
Shanxi & 0.7977 & 0.4639 & 0.752 & 0.5333 & 1.3087 & 0.0341 & 0.0043 & 0.0022 & 3.8962 \\
Anhui & 0.0417 & 0.0015 & 0.0647 & 0 & 0.0001 & 0 & 0 & 0 & 0.108 \\
Shandong & 0.0845 & 0.0885 & 0.1192 & 0.1917 & 0.0536 & 0.0115 & 0 & 0 & 0.549 \\
Henan & 0.0508 & 0.0271 & 0.1642 & 0.0251 & 0.0009 & 0.0084 & 0 & 0.0002 & 0.2767 \\
Hubei & 0.4959 & 0.3981 & 0.1611 & 0.0885 & 0.0065 & 0 & 0 & 0 & 1.1501 \\
Hunan & 0.0117 & 0.0098 & 0.0333 & 0.0014 & 0.0001 & 0 & 0 & 0 & 0.0563 \\
Chongqing & 0.2236 & 0.0884 & 0.031 & 0.124 & 0.0093 & 0 & 0 & 0 & 0.4763 \\
Sichuan & 1.1425 & 0.2269 & 0.3483 & 0.4901 & 0.0678 & 0.001 & 0 & 0.0002 & 2.2768 \\
Guizhou & 0.4213 & 0.0747 & 0.0217 & 0.3241 & 0.0081 & 0 & 0 & 0 & 0.8499 \\
Yunnan & 0.6404 & 0.482 & 0.4875 & 0.2214 & 0.0372 & 0.0015 & 0 & 0 & 1.87 \\
Shaanxi & 1.0032 & 0.738 & 0.7129 & 2.9451 & 0.8012 & 0.0387 & 0.0114 & 0.0061 & 6.2566 \\
Gansu & 0.3975 & 0.4047 & 0.4948 & 2.107 & 1.3866 & 0.0512 & 0.4804 & 0.1591 & 5.4813 \\
Ningxia & 0.0617 & 0.0214 & 0.0417 & 0.7805 & 0.7328 & 0.0339 & 0.0259 & 0.0146 & 1.7125 \\
Sum & 6.2503 & 3.2588 & 4.4378 & 8.1681 & 4.5055 & 0.2458 & 0.5244 & 0.1836 & 27.5743 \\
\hline
\end{tabular}


The provinces with considerable production potential for Pistacia chinensis are located in Southwest China. Yunnan is the province with the largest distribution area (4.64 million ha) of lands suitable for the growth of Pistacia chinensis. The area accounts for $25.39 \%$ of the total suitable area. Guizhou and Hubei Province come second, with a distribution area of 4.15 million ha and 2.21 million ha, respectively. Beijing has the smallest area of land suitable for the growth of Pistacia chinensis. Among the regions fairly suitable for the growth of Pistacia chinensis, Shaanxi Province comes first, with the area accounting for $22.69 \%$ of the total area of land fairly suitable for the growth of Pistacia chinensis. Gansu and Shanxi Province rank second. The provinces in North China have the largest area of land fairly suitable for the growth of Pistacia chinensis, while Hunan Province has the smallest area. Comprehensively speaking, the provinces with the largest production potential for Pistacia chinensis are Shaanxi, Yunnan and Gansu, accounting for $16.18 \%, 14.20 \%$ and $12.09 \%$ of the total area, respectively. The provinces with the lowest production potential for Pistacia chinensis are Tibet, Jiangsu and Beijing.

\subsection{Estimation of Biodiesel Potential from Pistacia chinensis}

Modification of the Assessment Results of Suitable Land Resources

The relevant national policies, laws and socio-economic factors all have a significant impact on the development and exploitation of land resources suitable for the growth of bio-energy crops. China's second phase of natural forest resource protection project mainly involves 17 provinces (districts and municipalities) at the upper reaches of the Yangtze River, the middle and upper reaches of the Yellow River, Inner Mongolia and Northeast China. In the provinces suitable for the growth of Pistacia chinensis in this study, shrub land serves as the major barrier because it provides biological services and protects the ecosystem. According to China's policies and regulations on forestry [23], shrub land should not be modified for other purposes. Thus, we exclude shrub land from the assessment results. The modified results are shown in Figure 4.

Figure 4. Post-correction area of each land use type suitable for planting Pistacia chinensis.

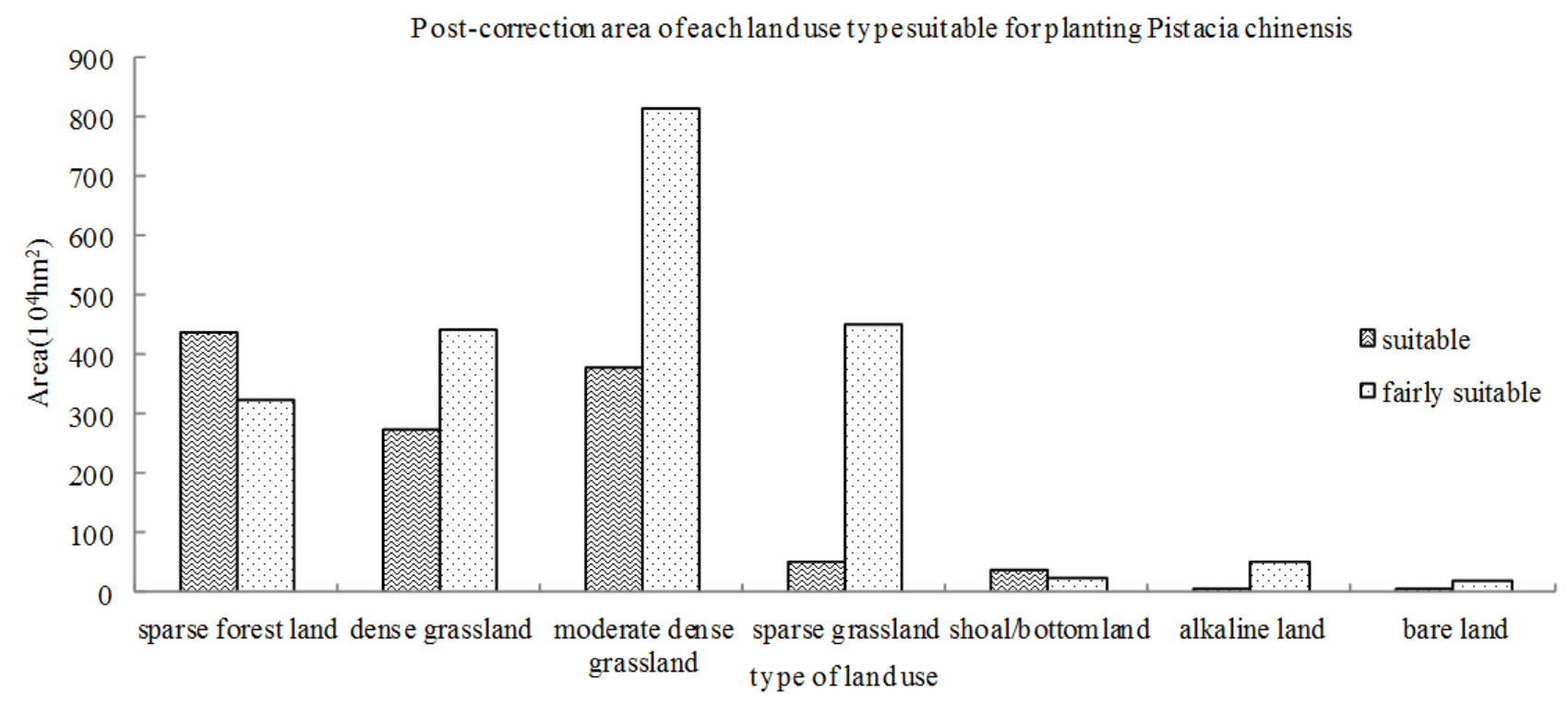


With shrub land excluded, the total area of various land types suitable for the growth of Pistacia chinensis is $\mathbf{1 1 . 8 4}$ million ha. The total area of land types fairly suitable for the growth of Pistacia chinensis is 21.32 million ha. Given the mean cultivation index of $60 \%$ [24], a total of 19.90 million ha of land can be used to cultivate Pistacia chinensis. Moderate dense grassland, which includes natural grassland and improved grassland with $20 \%-50 \%$ coverage, is the land use type with the largest area suitable for the growth of Pistacia chinensis after modification. The cultivable area is 7.18 million ha, accounting for approximately $36.10 \%$ of the area of suitable and fairly suitable lands. Sparse forest land and dense grassland rank second. Bare land is the land type with the smallest cultivable area of 0.11 million ha, accounting for $0.56 \%$ of the total cultivable area.

\subsection{Estimation of Biodiesel Potential from Pistacia chinensis}

According to previous literatures, the production of biodiesel from Pistacia chinensis per unit area of suitable and fairly suitable marginal land is about $3.5 \mathrm{t}$ per ha and $2.5 \mathrm{t}$ per ha, respectively [2]. According to the results of marginal land resources in Section 3.2.1., approximately 24.86 million $t$ of biodiesel can be produced from Pistacia chinensis in the suitable areas compared with 31.99 million $\mathrm{t}$ from the fairly suitable areas.

With consideration of the areas suitable and fairly suitable for the growth of Pistacia chinensis after modification, the provinces with the largest production potential are Shaanxi, Gansu and Yunnan, with 3.81 million ha, 3.08 million ha and 2.46 million ha of land, respectively. The annual mean biodiesel production is approximately 10.18 million $t, 7.75$ million $t$ and 7.88 million $t$. This is only a preliminary estimation based on available land resources and experimental production data. A more comprehensive assessment might be conducted in further steps when more factors were included, such as conversion efficiencies in the whole life cycle of bioenergy utilization, the ecological impact of large-scale cultivation of Pistacia chinensis, etc.

\section{Conclusions}

Since 2006, the Forestry Bureau, at the national and provincial levels, has formulated a program for the large-scale development of biodiesel from forestry. Under the support of the government and relevant enterprises, large-scale biodiesel forest bases are now being constructed. Some demonstration projects of forest-based biodiesel production have been officially approved by the government and are now under construction [25]. Provinces such as Hebei, Henan, Shaanxi and Anhui have already begun the planning of energy plant bases. In China, the forest-based biodiesel industry represented by Pistacia chinensis is now rapidly developing; as an emerging industry, however, its future development is confronted by challenges and uncertainty.

In this paper, we use land use, remote sensing, meteorological and soil data in combination with the requirements of Pistacia chinensis to tentatively assess land suitability for growing this species in China. The method we adopt is a multi-factor integrated assessment with the consideration of policy restraints. The conclusions proposed in this study are as follows:

(1) With consideration to policy and other constraints, China's total area of marginal land suitable for the growth of Pistacia chinensis is 19.90 million ha, the suitable area is 7.10 million ha and the 
fairly suitable area is 12.79 million ha. Approximately 56.85 million $\mathrm{t}$ of biodiesel can be produced from Pistacia chinensis.

(2) On the provincial level, Shaanxi has the largest potential of Pistacia chinensis production, followed by Gansu and Yunnan, with the area accounting for $19.14 \%, 15.50 \%$ and $12.38 \%$ of the total suitable area, respectively; the annual mean biodiesel production from Pistacia chinensis is approximately 10.18 million $\mathrm{t}, 7.75$ million $\mathrm{t}$ and 7.88 million $\mathrm{t}$, respectively. Located in the middle and upper reaches of the Yellow River, Shaanxi and Gansu are superior in moisture, temperature and sunshine conditions and are therefore suitable for the growth of Pistacia chinensis. Yunnan, with good moisture, temperature and sunshine conditions, has fertile soil and concentrated land resource distribution and is suitable for the large-scale cultivation of Pistacia chinensis. The provinces or municipalities with the smallest production potential are the Tibet Autonomous Region, Jiangsu and Beijing, with the suitable area being only $0.31 \%, 0.39 \%$ and $0.78 \%$, respectively. The Tibet Autonomous Region located in the plateau has good sunshine conditions but low precipitation and barren soil. Only a small suitable area for the growth of Pistacia chinensis is found in the south of Tibet. Beijing and Jiangsu, which have a developed economy and high land use intensity, are dominated by lands for agricultural and construction purposes, with less land for the growth of Pistacia chinensis.

(3) With regard to land use type, moderate dense grassland has the largest suitable area for the growth of Pistacia chinensis after the exclusion of shrub land, and its area accounts for approximately $36.10 \%$ of the suitable area and fairly suitable area. Dense grassland and sparse grassland come next. Grassland of barren hills is the major land type suitable for the growth of Pistacia chinensis. However, if a large area of this land type is used to grow Pistacia chinensis, the local development of animal husbandry will be seriously affected.

\section{Acknowledgments}

The work presented here was supported by the Chinese Academy of Sciences (Grant No. KZZD-EW-08) and National Natural Science Foundation of China (Grant No. 40830637).

\section{References}

1. Jiang, D.; Zhuang, D.F.; Fu, J.Y.; Huang, Y.H. Bioenergy potential from crop residues in China: Amount and availability. Renew. Sustain. Energy Rev. 2012, 16, 1377-1382.

2. Goran, B.; Julia, H. Bioenergy expansion in the EU: Cost-effective climate change mitigation, employment creation and reduced dependency on imported fuels. Energy Policy 2007, 35, 5965-5979.

3. Fu, Y.; Pan, X.B.; Gao, H. Geographical distribution and climate characteristics of habitat of Pistacia chinensis Bunge in China. Chin. J. Agrometeorol. 2009, 30, 318-322.

4. De Vries, S.C.; van de Ven, G.J.; van Ittersum, M.K.; Giller, K.E. Resource use efficiency and environmental performance of nine major biofuel crops, processed by first-generation conversion techniques. Biomass Bioenergy 2010, 34, 588-601. 
5. Smith, W.K.; Cleveland, C.C.; Reed, S.C.; Miller, N.L.; Running, S.W. Bioenergy potential of the United States constrained by satellite observations of existing productivity. Environ. Sci. Technol. 2012, 46, 3536-3544.

6. Shah, S.; Gupta, M.N. Lipase catalyzed preparation of biodiesel from Jatropha oil in a solvent free system. Process Biochem. 2007, 42, 409-414.

7. Tamalampudi, S.; Talukder, M.R.; Hama, S.; Numata, T.; Kondo, A.; Fukuda, H. Enzymatic production of biodiesel from Jatropha oil: A comparative study of immobilized-whole cell and commercial lipases as a biocatalyst. Biochem. Eng. J. 2008, 39, 185-189.

8. Achten, W.J.; Verchot, L.; Franken, Y.J.; Mathijs, E.; Singh, V.P.; Aerts, R.; Muys, B. Jatropha bio-diesel production and use. Biomass Bioenergy 2008, 32, 1063-1084.

9. Tapanes, N.O.; Aranda, D.G.; de Mesquita, J.W.; Antunes, O.C. Transesterification of Jatropha curcas oil glycerides: Theoretical and experimental studies of biodiesel reaction. Fuel 2008, 87, 2286-2295.

10. Hou, X.C.; Zuo, H.T.; Mou, H.X. Geographical distribution of energy plant Pistacia chinensis Bunge in China. Ecol. Environ. Sci. 2010, 19, 1160-1164.

11. Wang, T. A survey of the woody plant resources for biomass fuel oil in China. Sci. Technol. Rev. 2005, 23, 12-14.

12. Qin, F.; Guo, T.B.; Liu, Z.G.; Song, M.H. Literature review of researches on Pistacia chinensis Bunge. Nonwood For. Res. 2007, 25, 90-96.

13. Niu, Z.T.; Li, T.; Jian, G.Z.; Zhang, Y.J. Resource survey, cultivation techniques and multipurpose utilization of Pistacia chinensis Bunge. Nonwood For. Res. 2005, 23, 68-71.

14. Dunn, D.E.; Cole, J.C.; Smith, M.W. Position of cut, bud retention and auxins influence rooting of Pistacia chinensis. Sci. Hortic. 1996, 67, 105-110.

15. Onay, O. Fast and catalytic pyrolysis of pistacia khinjuk seed in a well-swept fixed bed reactor. Fuel 2007, 86, 1452-1460.

16. Borland, A.M.; Griffiths, H.; Hartwell, J.; Smith, A.C. Exploiting the potential of plants with crassulacean acid metabolism for bioenergy production on marginal lands. J. Exp. Bot. 2009, 60, 2879-2896.

17. Liu, J.Y;; Zhang, Z.X.; Zhuang, D.F.; Deng, X.Z.; Zhang, Z.X. Space pattern analysis of recently land use change in China. Sci. China Ser. D 2002, 32, 1031-1041.

18. Zhang, C.X. Potential and Impact Assessment of Bio-Ethanol in China. Ph.D. Dissertation, Graduate University of Chinese Academy of Sciences, Beijing, China, 2010.

19. Zhuang, D.F.; Jiang, D.; Liu, L.; Huang, Y.H. Assessment of bio-energy potential on marginal land in China. Renew. Sustain. Energy Rev. 2011, 15, 1050-1056.

20. Liu, L. The Potential and impacts of biofuel development for the five provinces in Southwest China. Ph.D. Dissertation, Graduate University of Chinese Academy of Sciences, Beijing, China, 2011.

21. Yuan, Z.Q.; Xiao, Y.P.; Liu, R.G.; Li, Z.Z.; Chen, X.; Li, Y.Z. Analysis and evaluation of marginal land resource for planting energy crops in Jiangxi province. Acta Agric. Jiangxi 2008, 20, 92-94.

22. Wu, Z.Z.; Xian, H.L.; Shang, Z.H.; Shao, Q. Analysis on geographical variation of fruit oil content of Pistacia chinensis. Sci. Silvae Sinic. 2009, 45, 69-73. 
23. Cao, Y.K.; Lv, T.; Chen, N.J. Analysis the impact on natural forest protection program to forestry policies in China. Issues For. Econ. 2011, 31, 377-382.

24. Shi, Y.L.; Kang, Q.Y.; Zhao, C.X.; Zhong, L.Y.; Shi, Z.Q. Margin Land Resource of Suitable for Agriculture in China, 3rd ed.; Beijing Science and Technology Press: Beijing, China, 1985.

25. Wu, W.G.; Huang, J.K.; Deng, X.Z. Potential land for plantation of Jatropha curcas as feedstocks for bio-diesel in China. Sci. China Ser. D 2009, 39, 1672-1680.

(C) 2012 by the authors; licensee MDPI, Basel, Switzerland. This article is an open access article distributed under the terms and conditions of the Creative Commons Attribution license (http://creativecommons.org/licenses/by/3.0/). 